\title{
Effect of dynamic strain aging on isotropic hardening in low cycle fatigue for carbon manganese steel
}

\author{
Zhi Yong Huang ${ }^{\mathrm{a}, *}$, Jean-Louis Chaboche ${ }^{\mathrm{b}}$, Qing Yuan Wang ${ }^{\mathrm{a}}$, Danièle Wagner ${ }^{\mathrm{c}}$, \\ Claude Bathias ${ }^{\mathrm{C}}$
}

a Sichuan University, School of Aeronautics and Astronautics, No. 29 Jiuyanqiao Wangjiang Road, Chengdu 610064, China

${ }^{\mathrm{b}}$ ONERA, DMSM, 29 avenue de la Division Lecerc, F-92320 Chatillon, France

' Université ParisOuest Nanterre La Défense, France

\begin{abstract}
A B S T R A C T
Carbon-manganese steel A48 (French standard) is used in steam generator pipes of nuclear reactor pressure vessels at high temperatures (about $200{ }^{\circ} \mathrm{C}$ ). The steel is sensitive to dynamic strain aging in monotonic tensile test and low cycle fatigue test at certain temperature range and strain rate. Its isotropic hardening behavior observed from experiments has a hardening, softening and hardening evolution with the effect of dynamic strain aging. The isotropic hardening model is improved by coupling the dislocation and dynamic strain aging theory to describe the behavior of $\mathrm{A} 48$ at $200{ }^{\circ} \mathrm{C}$.
\end{abstract}

Keywords:

LCF

DSA

High temperature

C-Mn steel

\section{Introduction}

In steam generator of PWR plants and feedwater lines connected to the loop pipes have been designed to withstand the internal pressure. In terms of the previous reports [1], these pipes also sustain long time and repeated alternation loads due to intermittent injection of cold water which introduces a stratified water distribution and forms cyclic thermal stress. Fatigue damage in the tubes is caused by the cyclic load. The fatigue life prediction for the notched or welded specimen is investigated by Berto and Lazzarin [2,3] by using volume based Strain Energy Density (SED) approach which gives a fatigue criteria and is used to correctly describe the fatigue behavior.

For metal materials, under loading (tensile, fatigue, etc), several metallurgical instabilities such as Lüders bands, Portevin le Chatelier bands, Neuman bands, twinning and phase transformation, are related with the spreading of solute atoms over crystal lattice or the crystallographic structure changing [4-6].

Dynamic Strain Aging (DSA) is a result of the interaction of strong solute atoms pinning and dislocations moving, which influence the mechanical characters of materials. The solute atoms are capable of diffusing over short distance and arrest mobile dislocations in certain strain rate and temperature range. The strain rate sensitivity coefficient becomes negative when DSA happens and the well known localized deformation bands

\footnotetext{
* Corresponding author. Tel./fax: + 862885406919.

E-mail address: huangzy@scu.edu.cn (Z.Y. Huang).
}

(Portevin-Le Chatelier) appear in the monotonic tensile test [7]. In the case of low cycle fatigue test, serrated yielding is also observed in the strain-stress curve [8].

Insufficiently killed steels are sensitive to DSA and lead to varying mechanical characters such as the increasing of flow stress, ultimate tensile strength (UTS), work hardening coefficient, and the decreasing of ductility and fracture toughness. Some typical characters of DSA in cyclic tests are reported in the literature [9-11]: inverse dependence of the peak tensile stress with strain rate and an unusual increase in the effect of DSA in the single phased ferrite austenitic stainless steels. Tsuzaki et al. [11] reported that the DSA sensitive temperature is lower in fatigue than in monotonic tensile for austenitic stainless steel. Abdel Raouf et al. [12] observed DSA hardening in the LCF test for low carbon steel.

The effect of DSA with loading speed on LCF behavior strongly depends on the material composition and the heat treatment. The article mainly focuses on the DSA effect on LCF isotropic hardening for the low carbon manganese steel. Double hardening in the peak tensile stress evolution is studied from the test results. In order to describe this behavior, an improved isotropic hardening constitutive model is proposed by considering the DSA effect, the interaction of dislocation movement and the solute atoms diffusion.

\section{Material and experiment}

The plates of steel A48 are selected to study. The material composition is shown in Table 1 . The steel has been semi-killed 
Table 1

Chemical composition (wt\%)

\begin{tabular}{|c|c|c|c|c|c|c|c|c|c|c|c|c|c|}
\hline Material & C & $S$ & $\mathrm{P}$ & $\mathrm{Si}$ & Mn & $\mathrm{Ni}$ & $\mathrm{Cr}$ & Mo & $\mathrm{Cu}$ & Sn & $\mathrm{Al}$ & $\mathrm{N}$ & $\mathrm{O}$ \\
\hline A 48 & 0.198 & 0.012 & 0.0104 & 0.207 & 0.769 & 0.135 & 0.095 & 0.025 & 0.273 & 0.023 & 0.004 & 0.0083 & 0.0049 \\
\hline
\end{tabular}

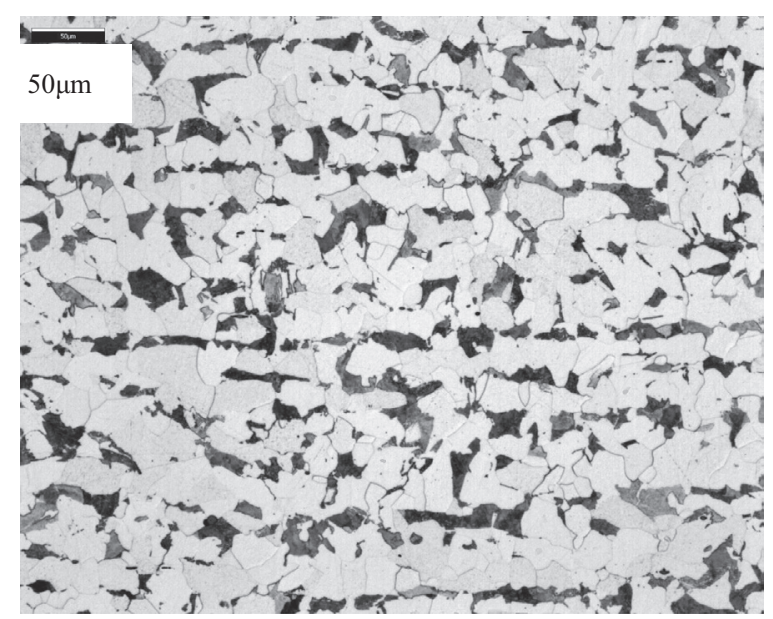

Fig. 1. Optical microstructure observation for steel A48.

Table 2

Mechanical properties of A48 $\left(20^{\circ} \mathrm{C}\right)$.

\begin{tabular}{llllll}
\hline $\begin{array}{l}\text { Type of } \\
\text { steel }\end{array}$ & $\begin{array}{l}\text { Elastic Modulus } E \\
(\mathrm{GPa})\end{array}$ & $\begin{array}{l}\text { Yield stress } \\
(\mathrm{MPa})\end{array}$ & $\begin{array}{l}\text { Density } \rho \\
\left(\mathrm{kg} / \mathrm{m}^{3}\right)\end{array}$ & $\begin{array}{l}\text { UTS } \\
(\mathrm{MPa})\end{array}$ & $\begin{array}{l}\text { Poisson } \\
\text { ratio }\end{array}$ \\
\hline A48 & 209 & 315 & 7850 & 510 & 0.3 \\
\hline
\end{tabular}

by silicon and normalized at $870{ }^{\circ} \mathrm{C}$ followed by air cooling, so that the aluminum content of this steel is low $(0.004 \%)$.

The material is a kind of duplex phase steel. The microstructure shows alternating bands of ferrite and pearlite (Fig. 1) which has segregated minor inter-dendritic elements (mainly manganese). The distance between the bands of pearlite is about $30-40 \mu \mathrm{m}$ for the steel. The width of the ferrite bands is about $30 \mu \mathrm{m}$; the average size of pearlite grain is about $10 \mu \mathrm{m}$ and it is smaller than the ferrite grain as shown in Fig. 1. Some mechanical properties of the steel at room temperature are listed in Table 2.

\section{Tests and results}

\subsection{Internal friction and monotonic tensile experiments}

Attenuation of vibration of a solid material is due to the internal friction which is an intrinsic property of the material and can be defined as the capacity of the solid material dissipating thermal energy when it sustains cyclic load in the elastic domain. The specimens for internal friction experiment were machined into $3 \mathrm{~mm}$ diameter, $50 \mathrm{~mm}$ gauge length in the quarter thickness of transverse direction of the plates. The mechanical spectrometry is obtained by measuring the dissipated energy inside of the material by loading a weak elastic deformation at different temperatures. A torsion pendulum was applied to study the internal friction in the temperature range $-20-300{ }^{\circ} \mathrm{C}$ at $5 \times 10^{-6} \mathrm{~s}^{-1}$ strain rate with $130 \mathrm{~K} \mathrm{~h}^{-1}$ heating rate. The internal friction $Q^{-1}$ was recorded as a function of the test temperature as shown in Fig. 2 [13].

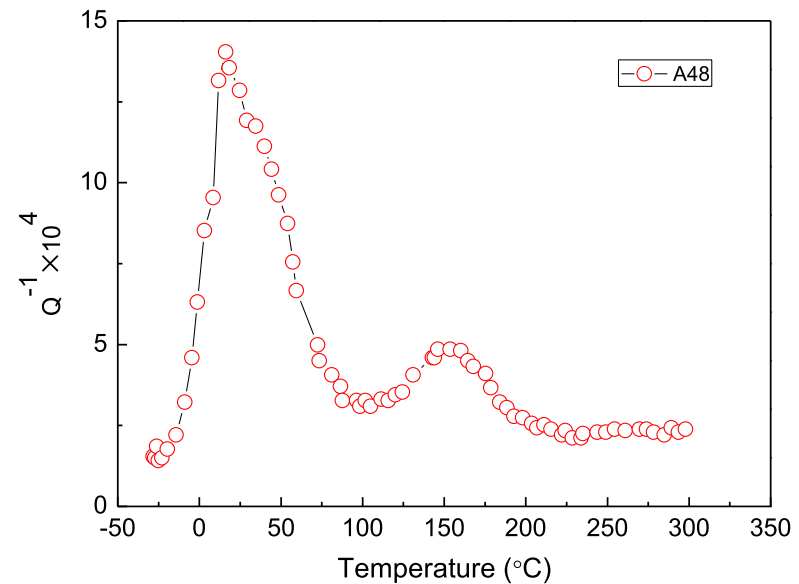

Fig. 2. Internal friction $Q^{-1}$ versus temperature for $A 48$ (normalized and cold worked condition) [13].

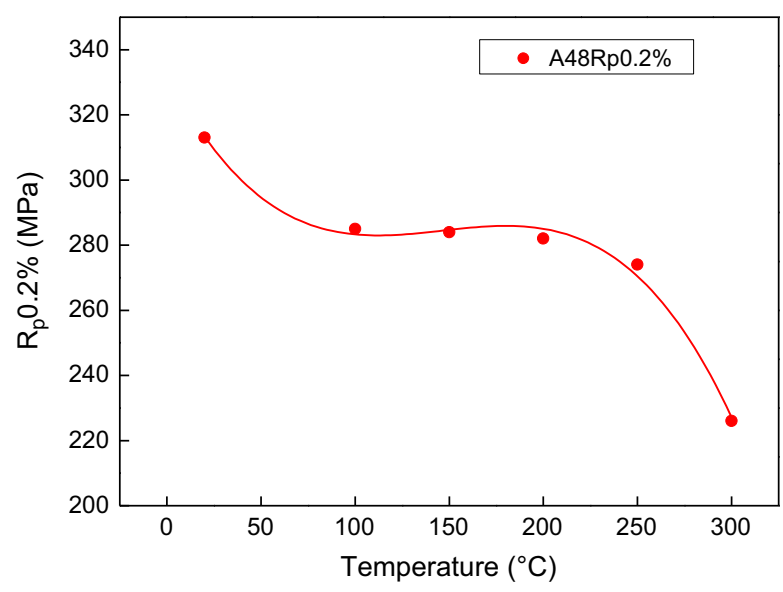

Fig. 3. Rp $0.2 \%$ changing with temperature increment for A48 [13]

In order to obtain the mechanical properties, the round specimens with $10 \mathrm{~mm}$ diameter were fabricated along the longitudinal direction of the A48 steel plates and the tensile tests were performed at strain rate $2.4 \times 10^{-4} \mathrm{~s}^{-1}$ in the same temperature range for the steel [13]. The yield stress, the ultimate tensile strength (UTS) and the final deformation were recorded and plotted as a function of the temperature in Figs. 3, 4 and 5 respectively.

\subsection{Fatigue tests}

Hydraulic fatigue test machine, Instron 8150 is applied to perform the LCF experiments at room and high temperatures in strain controlled by an extensometer with a triangular cyclic form load. The low cycle fatigue test specimen is designed as shown in Fig. 6. The evolutions of cyclic stress of the A48 steel are plotted in Fig. 7 with the growth of the number of cycles for $0.8 \%, 0.6 \%, 0.4 \%$ strain amplitude at $200{ }^{\circ} \mathrm{C}$ and $0.4 \% \mathrm{~s}^{-1}$ strain rate.

The cyclic stress evolutions of LCF at $200{ }^{\circ} \mathrm{C}$ experience two hardening and two softening stages for $0.4 \%, 0.6 \%$ and $0.8 \%$ strain 


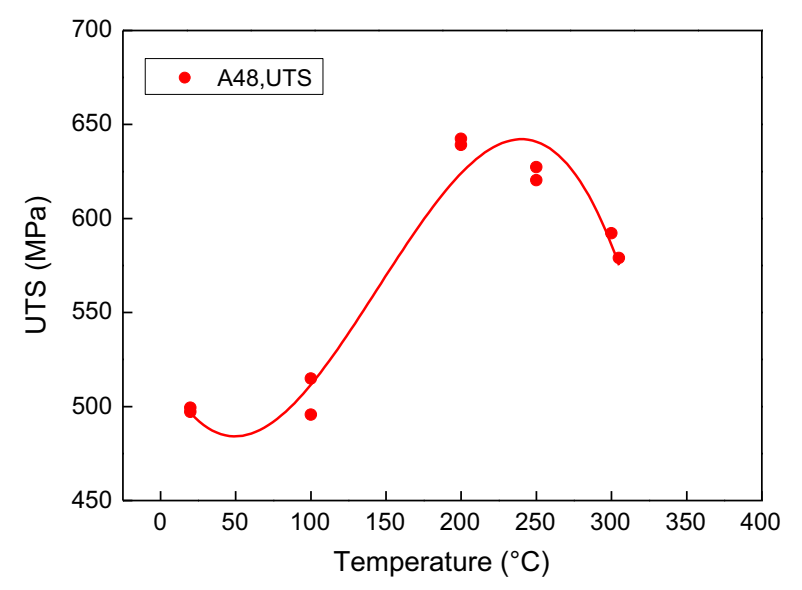

Fig. 4. Ultimate tensile strength versus temperature [13].

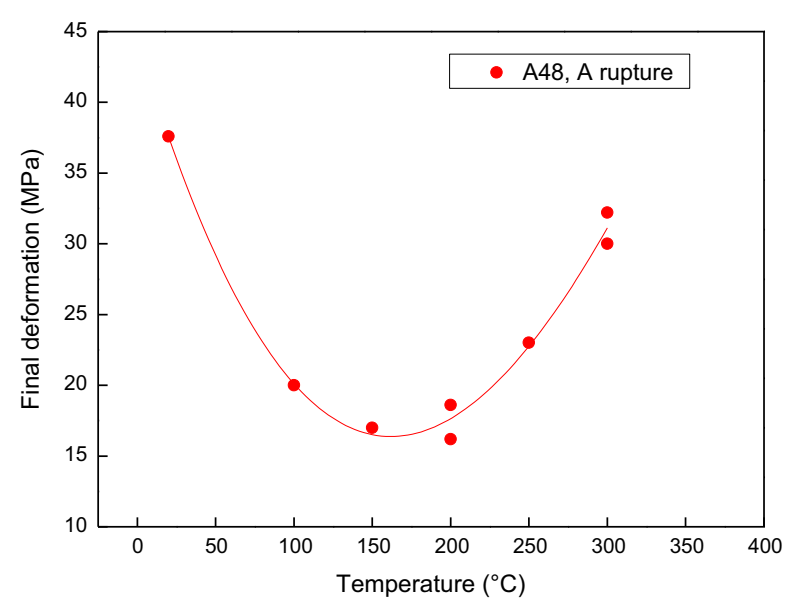

Fig. 5. Final deformation at rupture versus temperature [13].

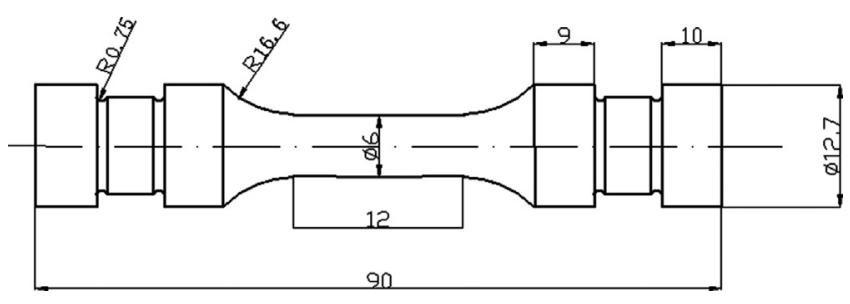

Fig. 6. Geometry of low cycle fatigue specimen.

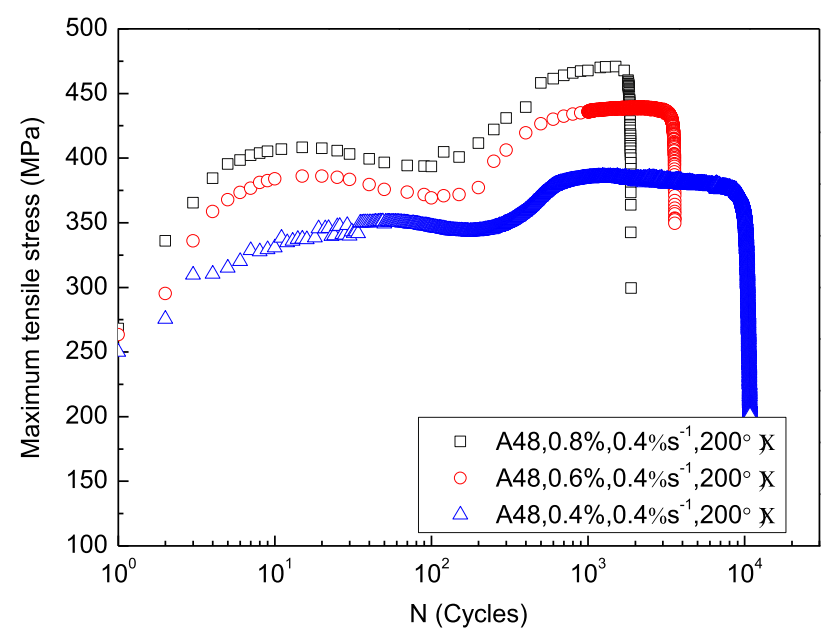

Fig. 7. Maximum tensile stress evolutions in LCF at $200{ }^{\circ} \mathrm{C}$ for $\mathrm{A} 48$.

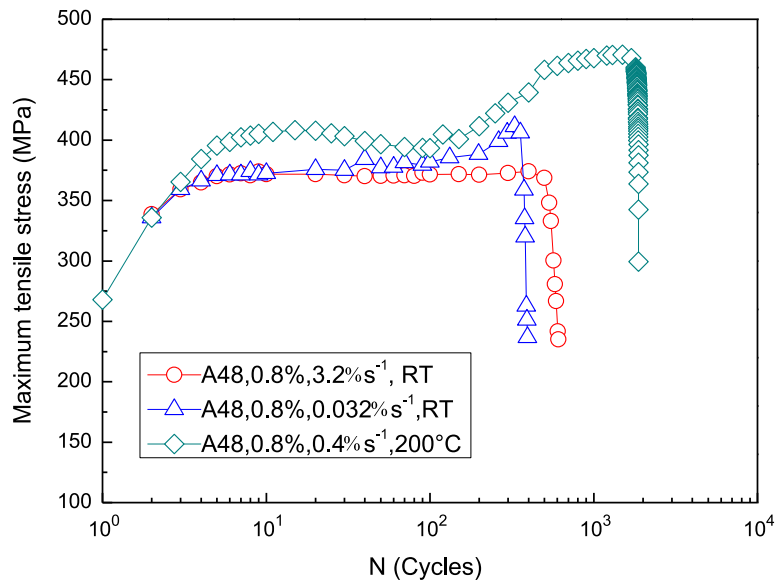

Fig. 8. A48 stress amplitude evolutions for $\varepsilon_{a}=0.8 \%$ with different strain rates.

amplitude as shown in Fig. 7. Between the first and second cyclic hardening, a remarkable cyclic softening appears. The stress amplitude decreases again before the end of the test induced by the presence of fatigue crack initiation and propagation. The period of second hardening takes about $90 \%$ of the fatigue life.

The LCF tests at room temperature are also performed at different strain rates but in the same strain amplitude $(0.8 \%)$ by comparing with the previous LCF test in $200{ }^{\circ} \mathrm{C}$ for A48 in Fig. 8 . The peak stress of the first cyclic hardening at $200{ }^{\circ} \mathrm{C}$ with $0.4 \%$ $\mathrm{s}^{-1}$ (diamond points) exceeds the corresponding stress at room temperature (round points), the room temperature and the slow strain rate $\left(0.032 \% \mathrm{~s}^{-1}\right)$ (triangle points).

\section{Discussion and modeling}

\subsection{Tensile peak stress evolution in $L C F$}

For the C-Mn steel, two kinds of atoms are extremely important: carbon and nitrogen. They are part of the solid solution of insertion into the centered cubic iron network, and their small size enables them to get inserted into the network and form solid solutions, or precipitates in the form of carbides (mainly iron $\mathrm{Fe}_{3} \mathrm{C}$ ), nitrides of aluminum and iron.

The atoms in the solid solution are distributed in 2 locations: the solid solution near the dislocations and the solid solution "free" in the network. The atoms at the second sites occupy the classical insertion sites such as: octahedral sites: midpoints of edges, centers of the faces of the cube, and tetrahedral sites. At the DSA sensitive temperature and strain rate, the diffusion rate of the atoms $\mathrm{C}$ and $\mathrm{N}$ is sufficient to follow and block the dislocations temporarily.

The 2 possible distributions depend on the presence or absence of some chemical compositions (aluminum or nitrogen), cooling after normalizing, and tempering treatment of post normalizing (relieving treatment after welding for example).

The internal friction experiments were implemented to evaluate the diffusion of carbon and nitrogen atoms interacting with mobile dislocations (Fig. 2). DSA is sensible to the strain rate and working temperature. For A48 steel, the temperature range at which DSA happens is between $100{ }^{\circ} \mathrm{C}$ and $350{ }^{\circ} \mathrm{C}$ (Figs. 3, 4 and 5) at $0.024 \% \mathrm{~s}^{-1}$. The higher temperature is helpful to the solute atoms to arrest the dislocations under LCF loads if the strain rate is greater.

At $200{ }^{\circ} \mathrm{C}$, the stress amplitude experiences a hardening-softening-hardening ( $\mathrm{HSH}$ ) process under $0.4 \%, 0.6 \%, 0.8 \%$ strain amplitude at $0.4 \% \mathrm{~s}^{-1}$ strain rate before the crack initiation (Fig. 7). 
The cyclic stress evolution has the second hardening in Fig. 7 which might be the result of the strong interaction between the mobile dislocations and the interstitial atoms of the metallic material [9]. The primary and the secondary hardening could have different mechanisms. But for the A48 steel at $200^{\circ} \mathrm{C}$, a significant cyclic softening appears between the two hardening periods clearly (Fig. 7).

The first hardening at $200{ }^{\circ} \mathrm{C}$ seems to be induced by the dislocations released from the pinning atoms and the additional dislocations multiplication and nucleation. The following cyclic softening behavior observed in Fig. 7 might indicate that the plastic deformation could be easier to take place under a relatively lower flow stress in the process of reorganization of mobile dislocations. The report [14] gave out TEM proofs that the dislocation density and structure (the formation of dislocation cells) changing due to the insufficient mobile dislocation locked by the interstitial atoms at cell wall leads to cyclic softening. The second cyclic hardening is more pronounced than the first one as shown in Fig. 8. It could be the effect of dynamic strain aging, dislocation and solute atoms (carbon and nitrogen) interaction in the LCF. Reference [12] also reported the secondary hardening in low carbon steel and concluded that the second hardening was due to the DSA effect. In Fig. 8, the dynamic strain aging influences the isotropic second hardening for A48 steel. Two times hardening in cyclic stress evolution could closely relate with the dislocations multiplication, nucleation and dynamic strain aging. The dislocation nucleation sites like the dislocation forest and the grain boundary being regarded as cell wall, could arrest dislocations and become obstacles for the dislocation movements during LCF strain loading. The fatigue behavior could be changed if the strain rate is not kept constant during the fatigue test like the sinusoidal form load. Same results are expected with other shapes of load waves. The important factor is the frequency which induces the strain rate. If the strain rate increases (increasing of dislocations gliding), the solute atoms do not follow the dislocations so well. Increase in the strain rate is identical with the decrease of temperature (which induces a decrease in the diffusion velocity of solute atoms).

\subsection{HSH process modeling}

In the paper, the cyclic stress experiences the hardeningsoftening-hardening (HSH) evolution from the experimental results for the material. As a preliminary modeling work, it is necessary to first study isotropic hardening/softening from the point of modeling with DSA effect for the sake of simplicity. Kinematic hardening should be added in the future in order to correctly describe the stress-strain hysteretic responses.

The isotropic hardening evolution with the effect of DSA for A48 steel could be divided into 3 main stages. The onset cycle of the hardening stages needs to be predicted firstly. The primary hardening starts from the first cycle by the observation of the curves (Fig. 7), but the beginning of the second hardening is difficult to be determined.

\section{Predicting the onset cycle of DSA hardening}

A total time of dislocations moving between cell walls such as cell shuttling motion is considered as [12]:

$t_{t}=t_{w}+t_{f}$

where $t_{w}$ is the waiting time at the cell wall and $t_{f}$ is the flight time across the cell structure. The flight time $t_{f}$ might be negligible because it is very short compared with the waiting time which is approximately considered as the same as the total time. The total time can be rewritten as [15]:

$t_{t} \approx t_{w}=\frac{w(p)}{\dot{p}}$

If the waiting time is long enough, with the dislocation multiplication (the results of the plastic deformations accumulation with the increase in the number of cycles), at a certain critical cycle, $N_{C}$, the aging time $t_{a}$ could just equal to $t_{w}$ and the waiting dislocations could be arrested largely at the cell walls [16].

$w(p)=w_{1}+w_{2}(p)$

The solute atoms such as carbon and nitrogen at $200{ }^{\circ} \mathrm{C}$ could get enough energy to follow and lock the dislocations at the cell walls. But the primary stage of isotropic hardening has not revealed the effect of DSA owing to the insufficient dislocations. At the DSA sensitive temperature, with the diffusion coefficient of interstitial atoms increasing, the aging time deceases and it is suitable to lock the mobile dislocations because of the increase in density at the cell walls with the increase in the number of cycles. The aging time is inversely proportional to the diffusion coefficient of solute atoms $D_{a}$ and the density of dislocation $\rho_{d}$ at cell walls [15] and can be expressed as:

$t_{a} \propto \frac{1}{\rho_{d} D_{a}}$

The dislocation density in cyclic deformation is assumed to grow linearly with the increase in accumulated plastic deformation. The total dislocations can be thought as

$\rho_{d} \propto \rho_{0} N \Delta \varepsilon_{p}$

where $\rho_{0}$ is the initial dislocation density within the cell; $N$ is the number of cycles and $\Delta \varepsilon_{p}$ is plastic strain range.

$\rho_{0}$ is a function of the average distance $L$ of cell wall which is considered as the cell size and can be determined by a transmission electron micrograph showing the dislocation cell structure of the material as reported in reference [16], so the aging time is proposed as

$t_{a}=K \frac{L^{2}}{N q D_{a}}$

where $K$ is a constant of proportionality. The condition of the DSA effect appearing in LCF is considered as

$t_{w}=t_{a}$

The critical cycle for onset of DSA hardening can be determined as

$N_{c}=K \frac{L^{2}}{q D_{a} t_{a}}$

where

$q=\frac{1}{2} \Delta \varepsilon_{p} \max$.

The diffusion coefficient $D_{a}$ can be expressed as

$D_{a}=D_{0} \exp \left(-\frac{Q}{R_{g} T}\right)$

$D_{0}$ is the temperature independent constant; $Q$ is the activation energy of the diffusion process and $R_{g}$ is the molar gas constant $[17,18]$. 


\section{Modeling HSH process}

As a preliminarily exploitation, the evolution of back stress is not included in the model. Isotropic hardening coupled with kinematic hardening with the effect of DSA would be studied in the future work. The isotropic hardening is considered and applied to the smooth specimen and the uniaxial stress may be expressed as $[19,20$

$\sigma=\sigma_{y}+\sum_{i} X^{(i)}+\sum_{k} R^{(k)}$

where $X^{(t)}$ is the back stress; $\sigma_{y}$ is the cyclic yield stress; $R^{(k)}$ is the isotropic hardening/softening stress. For A48 at $200^{\circ} \mathrm{C}$, the isotropic hardening/softening can be expressed as follows [21]:

$R=\sum_{k=1}^{3} R^{(k)}$

$\dot{R}^{(k)}=b_{c}^{(k)}\left(R_{c}^{(k)}-R^{(k)}\right) \dot{p}$

where $b_{c}^{(1)}$ is the primary cyclic hardening rapidity parameter; $b_{c}^{(2)}=\left\langle p-p_{c s}\right\rangle^{n_{1}}$ is proposed to describe the cyclic softening rapidity after the primary hardening with a accumulated plastic deformation threshold $p_{c s}$.

Owing to the influence of load amplitude, in the case of different strain amplitude of LCF, the $R_{c}^{(k)}$ (Eq. (12)) is the function of $q$ which is the plastic strain amplitude, a memory variable introduced by Chaboche [21]. In terms of the hardening-softening hardening evolutions and the stabilized response (Fig. 7), the model should depend on the strain range. The classical state variables for plasticity, kinematic hardening and isotropic hardening are not sufficient to describe the fatigue behavior. The cyclic response on isotropic hardening/softening needs the additional variable " $q$ " to store the current plastic strain amplitude.

$R_{c}^{(k)}=R_{M}^{(k)}-\left(R_{M}^{(k)}-R_{0}^{(k)}\right) \exp \left(-2 \mu^{(k)} q\right) \quad(k=1,2)$

where $R_{M}^{(k)}, R_{0}^{(k)}$ and $\mu^{(k)}$ are constants. The superscript $k=1,2$ means the first isotropic hardening and softening parameters respectively.

The DSA hardening in LCF can be calculated by [22]

$\dot{t}_{a}=1-\frac{t_{a}}{w(p)} \dot{p}$

$R_{c}^{(3)}=R_{a s}\left(R, t_{a}\right)=P_{1}\left(C_{1}+C_{2} R\right)\left[1-\exp \left(-P_{2} t_{a}^{m}\right)\right]$

The DSA could harden the cyclic stress when the accumulated plastic deformation reaches the secondary hardening threshold $\left(p_{a s}\right)$ or the critical cycle $\left(N_{C}\right)$ and may be expressed as

$\dot{R}^{(3)}=b_{a s}\left[R_{c}^{(3)}\left(R, t_{a}\right)-R^{(3)}\right] \dot{p}$

where

$p_{a s}=4 \sum_{n=1}^{N_{C}} \frac{\Delta \varepsilon_{p}(n)}{2}$

$b_{a s}=\left\langle p-p_{a s}\right\rangle^{n_{2} / 2 q}$

$b_{a s}$ is used to describe the speed to arrive at the second hardening peak stress. This period takes most of the fatigue life (about $90 \%$ fatigue cycles). The parameter might be closely related to the accumulated plastic deformation with a threshold $p_{a s}$, the accumulated plastic strain at cycle $N_{C}$ and the plastic deformation amplitude $q$.

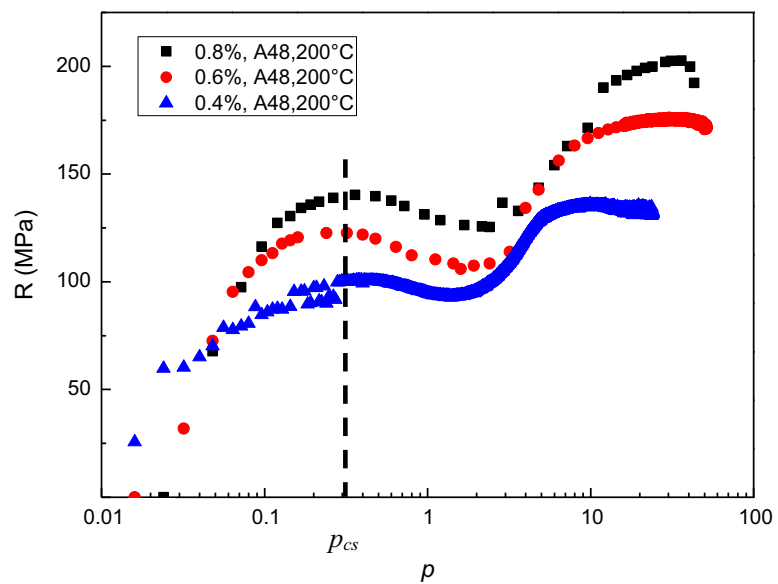

Fig. 9. Determination of the accumulated plastic deformation corresponding the onset of primary softening $\left(p_{c s}=0.3\right)$.

Table 3

Parameters of prediction of the second hardening model for A48 at $200{ }^{\circ} \mathrm{C}$.

\begin{tabular}{llllll}
\hline$Q(\mathrm{~J} / \mathrm{mol})$ & $D_{0}\left(\mathrm{~m}^{2} / \mathrm{s}\right)$ & $T(\mathrm{~K})$ & $R_{\mathrm{g}}\left(\mathrm{J} \mathrm{K}^{-1} / \mathrm{mol}\right)$ & $L(\mathrm{~m})$ & $K$ \\
\hline 84,100 & $2 \times 10^{-6}$ & 473 & 8.31 & $5 \times 10^{-7}$ & $6.3 \times 10^{-3}$ \\
\hline
\end{tabular}

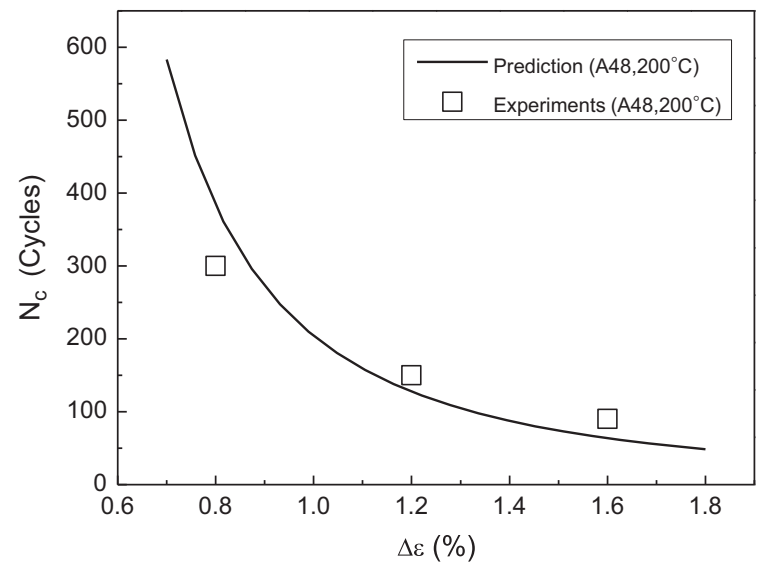

Fig. 10. Secondary hardening prediction and experimental results for A48 at $200{ }^{\circ} \mathrm{C}, 0.4 \% \mathrm{~s}^{-1}$.

\section{Identification and verification}

The paper aims to investigate the isotropic hardening with DSA effect on LCF. The isotropic hardening stress can be obtained by subtracting the back stress ( $X$ in Eq.(10)) and cyclic yield stress $\sigma_{y}$ in the hysteresis loops from the maximum cyclic stress of LCF tests results [23]. The cyclic yield stress $\left(\sigma_{y}\right)$ could be considered as a constant in the fatigue test. The evolution of isotropic hardening is obtained from the LCF test results and plotted in Fig. 9 with the growth of accumulated plastic deformation.

According to the A48 steel test results at $200{ }^{\circ} \mathrm{C}$ (Fig. 9), when the accumulated plastic deformation (the cyclic strain hardening) reaches $0.3\left(p_{c s}=0.3\right)$, the isotropic hardening almost attains the first peak as shown in Fig. 9.

The onset cycle of the secondary hardening $\left(N_{C}\right)$ is when the cell shuttling time for dislocations equals the aging time. The parameters are listed at Table 3 by referring to the reports $[14,15,19]$. The value of the proportionality coefficient $K$ is determined 
by the test. The $N_{C}$ prediction is shown and compared with the test results in Fig. 10.

Eqs. (11), (12), and (13) are used to describe the first cyclic hardening and the following softening for A48 in $200{ }^{\circ} \mathrm{C}$ with $0.4 \%$ $\mathrm{s}^{-1}$ through applying the parameters values determined by the test results as listed in Table 4. Fig. 11 gives out the primary isotropic hardening stress prediction.

The DSA effect on isotropic hardening is strain rate dependent, which is revealed by the aging stress $\left(R_{a s}\right)$ and can be determined by various strain rate tests. Plastic strain rate $\dot{p}$ is included in the DSA hardening term (Eqs. (14) and 15), an accumulated plastic strain $p$. By analyzing reference [21], the exponent parameter $m$ defines the size of the negative strain rate sensitivity domain; and $P_{2}, w$ could play the similar role to affect the delay of DSA. The evolutions of aging stress ( $R_{a s}$ for $0.8 \%, 0.6 \%, 0.4 \%$ strain amplitude) versus the plastic strain rate is shown in Fig. 12 (the parameters are listed in Table 5).

Eqs. (13)-(16) are applied to describe the A48 DSA hardening behavior. The onset cycle is predicted by Eq. (8) and is shown in

Table 4

Parameters of prediction of the first hardening and softening model for A48 at $200^{\circ} \mathrm{C}$

\begin{tabular}{ccccccccc}
\hline$b_{c h}$ & $n_{1}$ & $p_{c s}$ & $R_{M}^{(1)}(\mathrm{MPa})$ & $R_{0}^{(1)}(\mathrm{MPa})$ & $\mu^{(1)}$ & $R_{M}^{(2)}(\mathrm{MPa})$ & $R_{0}^{(2)}(\mathrm{MPa})$ & $\mu^{(2)}$ \\
\hline 13 & 1.2 & 0.3 & 185 & 10 & 90 & 55 & 5 & 20 \\
\hline
\end{tabular}

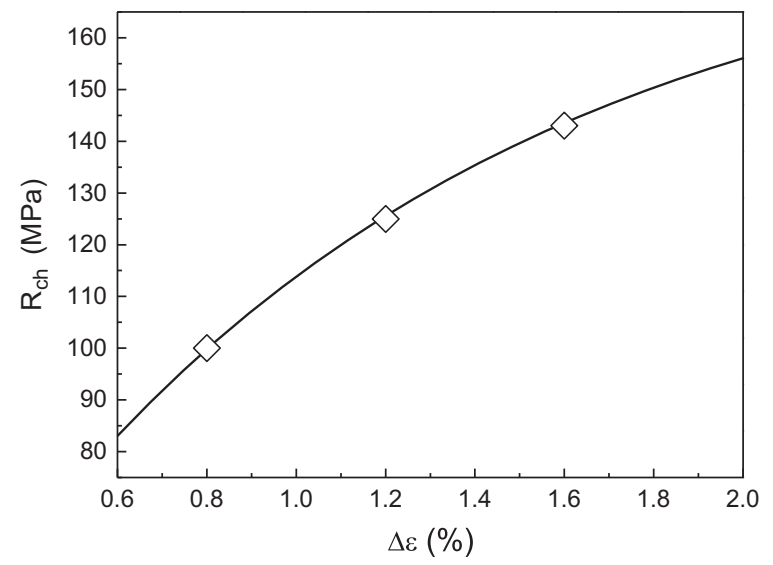

Fig. 11. Primary isotropic hardening stress versus total strain.

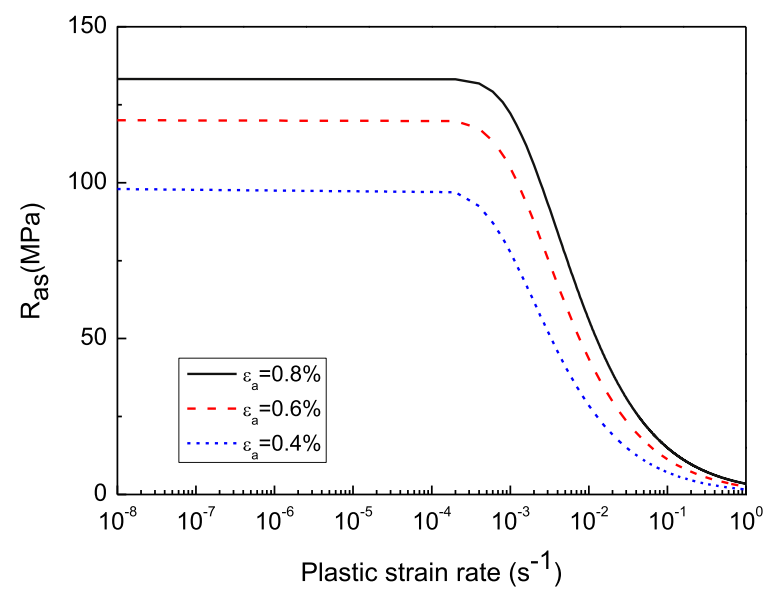

Fig. 12. Evolution of the aging stress with the strain rate.
Table 5

DSA hardening parameters for A48 at $200{ }^{\circ} \mathrm{C}$.

\begin{tabular}{llllll}
\hline$C_{1}$ & $C_{2}$ & $m$ & $P_{1}$ & $P_{2}$ & $n_{2}$ \\
\hline 8 & 0.7 & 0.66 & 2.4 & 0.4 & 0.0028 \\
\hline
\end{tabular}

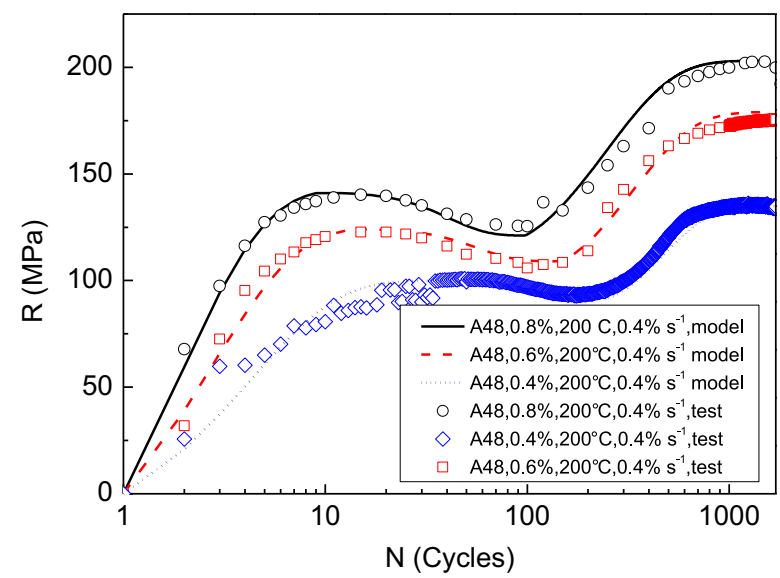

Fig. 13. Simulation for A 48 LCF cyclic hardening evolution at $200{ }^{\circ} \mathrm{C}$ with strain rate $0.4 \% \mathrm{~s}^{-1}$. (For interpretation of references to color in this figure, the reader is referred to the web version of this article.)

Fig. 10. The DSA hardening parameters are listed in Table 5 for Eqs. (15) and (16) and the values are taken from the reference literatures [19-21]. The empty black round, red square and blue diamond points denote $0.8 \%, 0.6 \%, 0.4 \%$ experimental isotropic hardening stress at $200{ }^{\circ} \mathrm{C}$, and the continuum black, discontinuous red and blue spotted lines are the simulation results respectively in Fig. 13.

\section{Conclusions}

This paper investigates the pronounced double isotropic hardening behavior of A48 steel in LCF. The material presents some special mechanical characteristics caused by DSA effect in monotonic tensile tests and LCF tests. The conclusions are as follows:

1. At high temperature, $200{ }^{\circ} \mathrm{C}$, the stress amplitude evolution of the steel (A48) reveal hardening, softening and hardening process before crack initiation. The primary hardening seems to be caused by the cyclic plastic deformation and the dislocation nucleation effect, but the second isotropic hardening could be induced by the DSA effect.

2. Based on the constitutive model of isotropic hardening, some improvements are made by considering the DSA effect. A critical number of cycles are introduced to the model in order to predict the onset cycle of the second hardening; the DSA stress dependent on the strain rate is evaluated to describe the isotropic HSH behavior. Compared with the test results, the improved model seems to be good to describe the behavior.

\section{Acknowledgments}

Cooperation with AREVA is gratefully acknowledged, especially the support of Professor T. Palin-Luc in ENSAM Bordeaux for the LCF experiments at high temperature. Financial support by the National Natural Science Research Foundation of China (No. 51101107 and No.11372201) is also gratefully acknowledged. 


\section{References}

[1] Z.Y. Huang, D. Wagner, C. Bathias, J.L. Chaboche, Int. J. Fatigue 33 (2011) $115-121$.

[2] F..Berto, P..Lazzarin, Theor. Appl. Fract. Mech. 52 (2009) 183-194.

[3] F. Berto, P. Lazzarin, Int. J. Fatigue 33 (2011) 1055-1065.

[4] R. Borrely, D. Benkirat, Acta Metall. 33 (5) (1985) 855-866.

[5] L. Cheng, N.M. van der Pers, A. Bottoger, T.h.H. deKeijser, E.J. Mittemeijer, Met. Trans. 22A (1991) 1957-1967.

[6] A.H. Cottrell, B.A. Bilby, Proc. Phys. Soc. 62/I-A (1949) 49-62.

[7] N. Ranc, D. Wagner, Mater. Sci. Eng. A. 394 (1-2) (2005) 87-95.

[8] V.S. Srinivasan, M. Valsan, R. Sandhya, K.Bhanu Sankara Rao, S.L. Mannan, D.H. Sastry, Int. J. Fatigue 21 (1999) 11-21.

[9] M. Yaguchi, M. Yamamoto, T. Ogata, Int. J. Plast. 18 (2002) 1083-1109.

[10] D. Yu, X. Chen, W. Yu, G. Chen, Int. J. Plast. 37 (2012) 119-139.

[11] Kaneaki Tsuzaki, Takashi Hori, Tadashi Maki, Imao Tamura, Mater. Sci. Eng. A. 61 (3) (1983) 247-260.
[12] H. Abdel-Raouf, A. Plumtree, T.H. Topper, ASTM-STP 519 (1973) 28-32.

13] D. Wagner, N. Roubier, C. Prioul, Mater. Sci. Technol. 22-23 (2006) 301-307.

[14] T. Mayama, K. Sasaki, H. Ishikawa, Int. J. Plast. 23 (2007) 915-930.

[15] F.A. McClintock, A. Argon, Mechanical Behavior of Materials, Addison-Wesley, New York, 1966.

[16] B.H. Lee, I.S. Kim, J. Nucl. Mater. 226 (1995) 216-225.

[17] P.G. McCormick, Acta Metall. 36 (12) (1988) 3061-3067.

[18] S. Zhang, P.G. McCormick, Y. Estrin, Acta Mater. 49 (2001) 1087-1094.

19] M. Mazière, H. Dierke, Comput. Mater. Sci. 52 (2012) 68-72.

[20] Y. Estrin, P.G. McCormick, Acta Metall. Mater. 39 (12) (1991) 2977-2983.

[21] J.L. Chaboche, Int. J. Plast. 24 (10) (2008) 247-302.

[22] J.-L. Chaboche, A. Gaubert, P. Kanouté, A. Longuet, F. Azzouz, M. Mazière, Int. J. Plast. 46 (2012) 1-22.

[23] J. Lemaître, J.L. Chaboche, Mechanics of Solid Materials, Cambridge University Press, Cambridge, 1990 